\title{
Lymphocyte Subsets and Specific IgG Antibody Levels in Clindamycin-Treated and Untreated Dogs Experimentally Infected with Babesia gibsoni
}

\author{
Retno WULANSARI ${ }^{1)}$, Agus WIJAYA ${ }^{1)}$, Hitoshi ANO $^{1)}$, Yoichiro HORII ${ }^{1)}$ and Susumu MAKIMURA ${ }^{1) *}$ \\ ${ }^{1)}$ Laboratory of Veterinary Internal Medicine, Department of Veterinary Science, Faculty of Agriculture, Miyazaki University, Miyazaki \\ 889-2192, Japan
}

(Received 13 September 2002/Accepted 18 January 2003)

ABSTRACT. This study was carried out to clarify the role of lymphocyte subpopulations and Babesia-specific antibody on the treatment of clindamycin in dogs infected with $B$. gibsoni. Ten beagle dogs were divided into two groups: an untreated group (5 dogs) and a clindamycin-treated group ( $5 \mathrm{dogs}$ ), which was administered clindamycin at $25 \mathrm{mg} / \mathrm{kg}$ body weight, per os, q $12 \mathrm{hr}$ from $7 \mathrm{days}$ to $21 \mathrm{~d}$ ays post-infection (PI). On the acute stage of infection, clindamycin treatment resolved anaemia and other clinical findings. There were no significant differences between treated and untreated dogs either in parasitemia levels or Babesial IgG antibody levels. However, morphological changes that indicated degeneration in the majority of parasites were observed. The numbers of $\mathrm{CD}^{+}$showed a significant increase in treated dogs, especially after treatment. On the chronic stage, $\mathrm{CD} 4^{+}$cells maintained high level both of the treated and untreated dogs. Although parasitemia maintained low level, their relapses were occurred on the 49th day PI in treated dogs and on the 42nd and 63rd PI in untreated dogs. A rapid humoral antibody response was observed in treated dogs, however, lower humoral anti body responses in untreated dogs after relapses. The antibody levels of treated dogs were significantly higher than those of untreated dogs. These results suggested that clindamycin might not eliminate rapidly parasites from peripheral blood, but damage parasites, whic $\mathrm{h}$ might stimulate efficiently humoral and cellular immunity against Babesia infection, and result in an improvement of clinical conditions. KEY WORDS: anti-Babesial antibody, Babesia gibsoni, canine, clindamycin, lymphocyte subset.

J. Vet. Med. Sci. 65(5): 579-584, 2003

Babesia gibsoni (B. gibsoni) infection in dogs has long been problematic in Japan, especially in the western region. In recent years, the geographic range of this infection has spread to the eastern region of Japan. Diminazene aceturate (Ganazeg) [10], phenamidine isethionate (Lomadine) [11], and pentamidine isethionate (Lomidine) [10] have demonstrated efficacy against B. gibsoni infection. In Japan, however, only the one drug, diminazene aceturate, has been utilized for the treatment of B. gibsoni infection. Although this medicine is effective against $B$. gibsoni, it sometimes induces side effects such as weakness, irritability, paralysis, non-responsiveness to stimuli, and fatal central nervous system haemorrhage [7]. Notably, production of this drug was recently stopped. Therefore, for effective treatment of $B$. gibsoni, an alternative chemotherapeutic agent having few side effects is urgently needed. Clindamycin has been successfully used for the treatment of B. microti infection in hamsters and humans, and for the treatment $B$. canis infection in $\operatorname{dogs}[5,9,14,18]$. Our previous studies indicated that clindamycin was successful for the treatment of $B$. rodhaini infection in mice, and might induce resistance to challenge infection in cured mice [21].

Both humoral and cellular factors are involved in immunity to babesiosis. However, information is very limited regarding the immune systems as the body defence reaction as he host in Babesia infection. This study was carried out to clarify the role of lymphocyte subpopulations and Babesia-specific antibody on the treatment of clindamycin in

* Correspondence to: Makimura, S., Laboratory of Veterinary Internal Medicine, Faculty of Agriculture, Miyazaki University, Miyazaki-shi 889-2192, Japan. dogs infected with B. gibsoni.

\section{MATERIALS AND METHODS}

Parasites: The strain of parasites used in this study was obtained from naturally infected mongrel dogs in Miyazaki Prefecture in Japan, that were identified with B. gibsoni according to nucleotide sequences of ribosomal DNA of the parasites [4]. This strain was maintained in our laboratory by passage from dog to dog during the period of the experiments.

Experimental animals: Ten, 1-year-old, parasite-free, male beagles were obtained from Medicinal Safety Research Laboratories, Sankyo Co., Ltd. Sizuoka, Japan and maintained in a closed environment in the authors' laboratory for one month prior to the study. All dogs received a physical examination, vaccinations against distemper and parvovirus, and were de-wormed if necessary. The dogs were put in separate cages and were given a limited daily volume of standard dog diet and tap water. Peripheral blood smears from all of the dogs are negative for Babesia sp. before infection was induced.

Experimental design: Beagle dogs were experimentally inoculated intravenously (i.v) with $2 \times 10^{9}$ parasitized erythrocytes, which were harvested from a splenectomized carrier dog at $13 \%$ of parasitemia. These Babesia-infected dogs were divided into two groups: untreated dogs (5 dogs) and clindamycin-treated dogs (treated $\operatorname{dog} s / 5 \operatorname{dogs}$ ). Clindamycin phosphate (Dalacin/CF, Up John Co., Tokyo) was orally administered at $25 \mathrm{mg} / \mathrm{kg}$ body weight, twice a day from 7 days until 21 days after infection. In this experiment, 
the infected dogs were observed until 3 months after infection.

Blood samples were collected intravenously at days 0,7 , $14,21,35,49,63$ and 82 . Blood for counting the number of lymphocytes and monocytes and ELISA serology was collected every week until 82 days after infection.

The packed cell volume was determined using an automatic blood cell counter (Sysmex K-4500, Sysmex Co., Tokyo). Blood smears were stained using May-Grundwald and Giemsa stains in order to measure parasitemia and evaluate leucocytes differential. Parasitemia levels were determined by counting the number of parasitised cells in 1,000 erythrocytes.

The reagents used for flow cytometry: The antibody for canine lymphocyte subsets measurement by flow cytometry (FCM), consist of primary antibody (rat anti-canine $\mathrm{CD}^{+}$, rat anti-canine $\mathrm{CD}^{+}$, Mouse anti-canine $\mathrm{CD} 21^{+}$, Serotec Ltd., U.S.A.) and secondary antibody (goat anti-rat IgG (H+L)- FITC, Caltag, U.S.A., Sheep anti-mouse IgG (H+L)-FITC, Serotec, Ltd., U.S.A.). Hemolyzing solution consisted of: $4.15 \mathrm{~g}$ of $\mathrm{NH} 4 \mathrm{CL}, 0.5 \mathrm{~g}$ of $\mathrm{KHCO}_{3}, 0.0186 \mathrm{~g}$ of $\mathrm{Na}_{2}$-EDTA and diluted in $50 \mathrm{~m} l$ distilled water and kept at $4{ }^{\circ} \mathrm{C}$ until use.

Analysis of flow cytometry: Heparinized peripheral whole blood samples were collected from radial veins. One-hundred $\mu l$ of peripheral whole blood was added to $10 \mu l$ of 50 times dilution of primary antibody, and then incubated for $30 \mathrm{~min}$ on ice. The blood samples were hemolyzed by the addition of warm hemolyzing solution, and centrifuged at $1,600 \mathrm{rpm}$ for $5 \mathrm{~min}$ at $4^{\circ} \mathrm{C}$. Secondary antibodies, which were $1.4 \mu \mathrm{l}$ of 50 dilutions of goat anti-rat $\operatorname{IgG}(\mathrm{H}+\mathrm{L})$-FITC, or $10 \mu l$ of sheep anti-mouse IgG $(\mathrm{H}+\mathrm{L})$-FITC were added to packed cells with $50 \mu l$ of cold Hanks balanced salt solution (-) (HBSS), then incubated for $30 \mathrm{~min}$ on ice. After incubation, the samples were re-suspended in $1 \mathrm{~m} l$ of cold HBSS and centrifuged again at 1,600 rpm for $5 \mathrm{~min}$ at $4^{\circ} \mathrm{C}$. The supernatant then was removed. The precipitate was added to $0.5 \mathrm{~m} l$ of cold HBSS and lymphocyte subsets were measured using a flow cytometer (EPICS XL, BECMANCOULTER, U.S.A.). List mode data were collected for 10,000 cells. Fluorescence analysis was performed on a lymphocyte gate by forward and side scatter.

Antibody detection: Babesia lysate antigen (BLA) for ELISA was prepared according to our method [2]. ELISA was performed using a modification of the method of Ishikawa et al. [13]. BLA (20 mg protein $/ \mathrm{m} l)$ was diluted at 1: 320 in carbonate buffer ( $\mathrm{pH} 9.6)$ and each $50 \mu \mathrm{l}$ per well were used to coat each well of 96-well microplates (Falcon 3912, Becton Dickinson, CA, U.S.A) and were left overnight at $+4^{\circ} \mathrm{C}$. The plates were washed four times in $0.05 \%$ Tween 20-PBSS (0.05\% Tw-PBS), then $200 \mu \mathrm{l}$ of $4 \%$ Bovine serum albumin (BSA) in PBS was added to each well, which was incubated at $37^{\circ} \mathrm{C}$ for $1 \mathrm{hr}$. After washing as described above, $50 \mu \mathrm{l}$ of test serum diluted at 1:100 with PBS containing $0.05 \%$ Tween 20 and $0.1 \%$ BSA was added to each well. After incubation at $37^{\circ} \mathrm{C}$ for $30 \mathrm{~min}$, each well was washed again and filled with $50 \mu l$ of peroxidase-conju- gated goat anti-dog immunoglobulins (IgG-HRP) diluted at 1:2,000 with the same buffer as used for the test serum. These conjugates were incubated at $37^{\circ} \mathrm{C}$ for $1 \mathrm{hr}$. The conjugates were washed again five times. Fifty $\mu l$ of $2 \mathrm{mg}$ ortho-phenylene-diamine (DAKO A/S, Denmark) in $30 \mathrm{ml}$ of distilled water and $1.25 \mu \mathrm{l}$ of $30 \%$ hydrogen peroxide were added to each well. The plate was incubated at room temperature for $20 \mathrm{~min}$. Colorimetric reaction was terminated by the addition of $50 \mu \mathrm{l}$ of sulphuric acid $(0.5 \mathrm{M})$ to each well. Thereafter the well contents were measured at $490 \mathrm{~nm}$ absorbance using a micro ELISA spectrophotometer (Precision, microplate reader, Emax, U.S.A.).

Data were expressed as the mean values \pm standard deviation. Student's $t$ test was used to determine significant differences among the data.

\section{RESULTS}

Blood examinations: Clindamycin-treated and untreated dogs experimentally inoculated with $B$. gibsoni showed peak parasitemia levels of $3.37 \pm 0.40$, and $4.53 \pm 1.50 \%$, respectively on the 14th day after infection. Then the levels of parasitemia in treated dogs tended to be lower than those of untreated dogs until the 63rd day after infection. Treated dogs showed only two slight relapses on days 49 and 82 , while untreated dogs showed more than four relapses (Fig. 1-A). The packed cell volume (PCV) of untreated and treated dogs began to decrease by the 7 th day, and in untreated dogs the PCV remarkably reached the minimum values $(14.4 \pm 1.6 \%)$ on the 28 th day after which they increased. On the other hand, the PCV of treated dogs decreased gradually until the 14th day, then began to increase and recovered almost to control levels on the 36th day (Fig. 1-B). Lymphocyte percentages showed an increase in the acute stage from the 7 th to 21 st day after infection and on the chronic stage from the 56th to the 82nd day. Lymphocytes of treated dogs showed a constant increase, especially after clindamycin treatment, and tended to be higher than those of untreated dogs, and were notably higher on the 28th and the 63rd day (Fig. 1- C). Monocytes increased from the 7 th to the 21 st day after infection. The numbers of monocytes of treated dogs were significantly higher than those of untreated dogs after clindamycin treatment on the 28th and the 35th day PI and then decreased during the chronic stage (Fig. 1-D). After relapses occurred on the 49th day PI, these numbers increased.

The majority (approximately $70 \%$ ) of B. gibsoni parasites in erythrocytes of untreated dogs demonstrated typical morphology (Fig. 2, A), e. g. small and rounded shape with clear cytoplasm and clear nuclear in the edge of the cell in May-Grunwald Giemsa stained blood smears in untreated on the 14th and 19th. Conversely, B. gibsoni parasites in clindamycin- treated dogs (Fig. 2, B-D) demonstrated morphological changes that indicated a significant incidence of parasite degeneration on the 14th (approximately 50\%) and the 19th (approximately 85\%); these degenerative changes included segmentation of nuclear localized in the cell limbic 

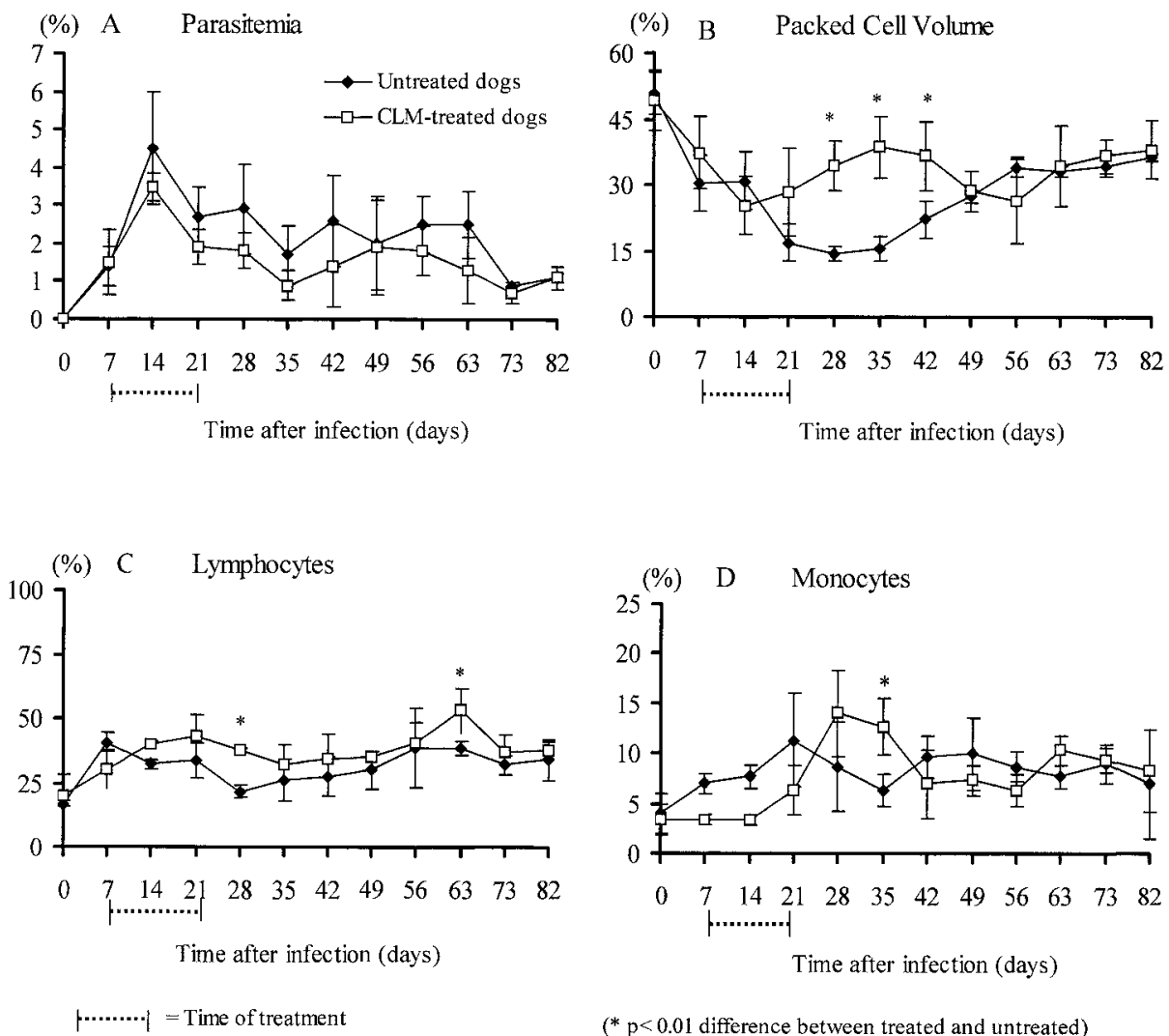

Fig. 1. Changes of parasitemia (A), packed cell volume (B), lymphocyte (C) and monocyte counts (D) in untreated $(\checkmark)$ and clindamycin treated $(\square)$ dogs infected with B. gibsoni. Dogs were experimentally inoculated intravenously with $2 \times 10^{9}$ parasitized erythrocytes. There were no significant differences between treated and untreated dogs either in parasitemia on the acute stage. Clindamycin treatment resolved anemia in the acute stage. After treatment, either lymphocytes or monocytes were higher in treated dogs than those in untreated.

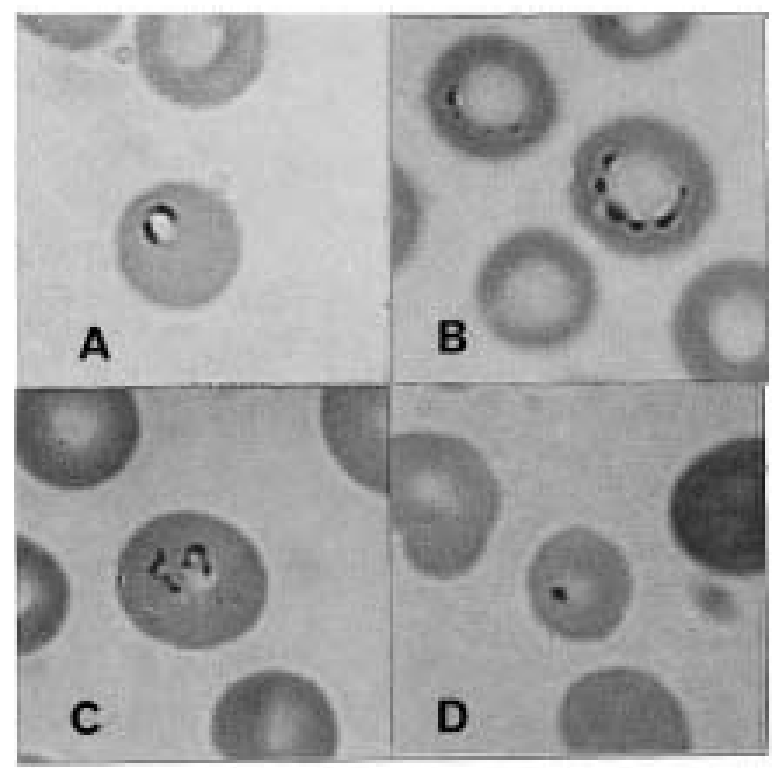

(Fig. 2, B); torn state (Fig. 2, C); and size-reduction of nuclear and disappearance of cytoplasm (Fig. 2, D).

Lymphocyte subsets: $\mathrm{CD} 4{ }^{+}$cells increased significantly on the 7th day after infection compared with values before infection. $\mathrm{CD}^{+}$cells of treated dogs were significantly higher than those of untreated on the 21st, 35th, and 82nd day after infection. $\mathrm{CD}^{+}$cells increased on the 7 th day compared with prior to infection. The numbers of $\mathrm{CD} 8^{+}$ cells of untreated dogs as significantly higher than those in

Fig. 2. Morphological changes of B. gibsoni on May-Grunwald Giemsa stained blood smears in untreated (A) and clindamycintreated (B-D) on the 14th and the 19th days after the infection. Almost parasites of untreated dogs showed typical morphology, e.g. small and rounded shape with clear cytoplasm and clear nuclear in the edge of the cell (A). The majority of parasites in clindamycin-treated dogs demonstrated morphological changes that indicated a significant incidence of parasite degeneration; these degenerative changes included segmentation of nuclear localized in the cell limbic (B); torn state of nuclear (C); sizereduction of nuclear and disappearance of cytoplasm (D). 


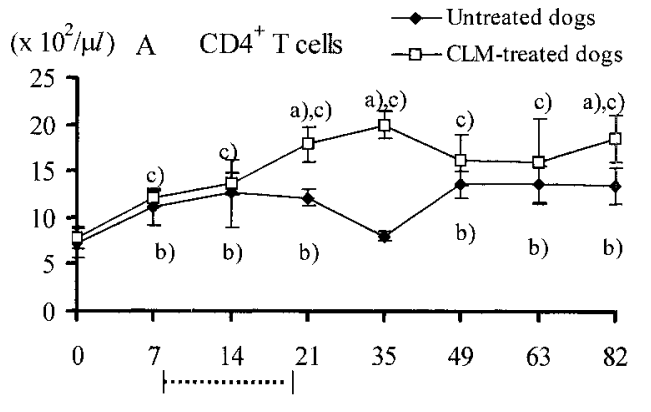

Time after infection (days)

C $\quad \mathrm{CD}^{+}: \mathrm{CD}^{+}$ratio

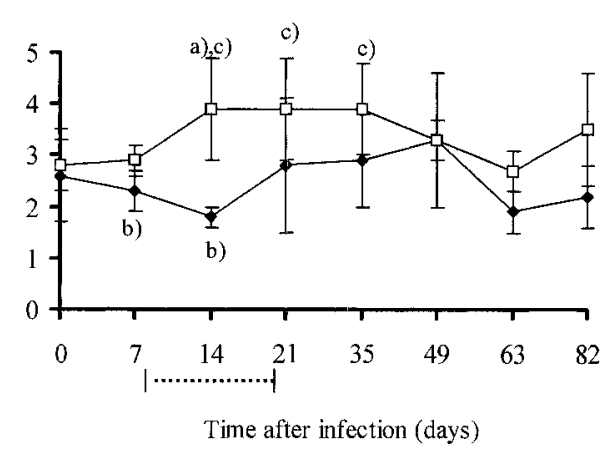

a) $\begin{aligned} & \mathrm{p}<0.05, \text { significant difference between treated } \\ & \text { and untreated }\end{aligned}$
................. $=$ Time of treatment $\left(\mathrm{x} 10^{2} / \mu l\right) \quad \mathrm{B} \quad \mathrm{CDB}^{+} \mathrm{T}$ cells

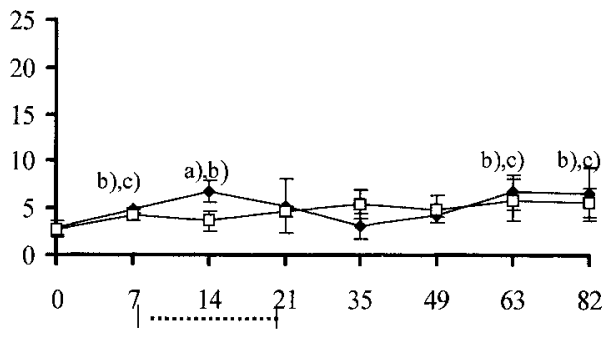

Time after infection (days)

$\mathrm{D} \quad \mathrm{CD} 21^{+} \mathrm{B}$ cells

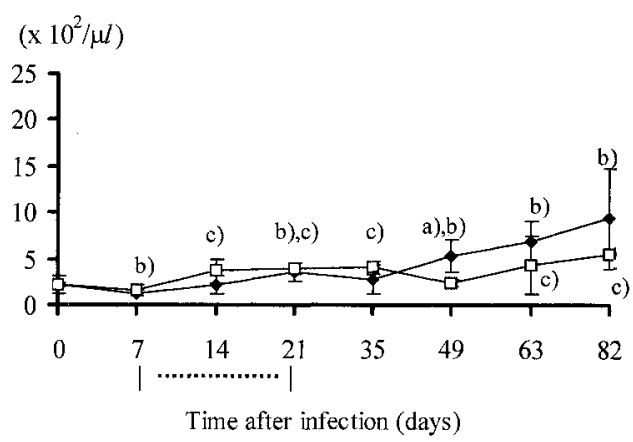

b) $p<0.05$, significant different before infection of untreated

c) $\mathrm{p}<0.05$, significant different before infection of treated

Fig. 3. Changes of lymphocyte subset levels (A. CD4 peripheral blood of untreated $(\diamond)$ and clindamycin treated $(\square)$ dogs infected with $B$. gibsoni. CD4 ${ }^{+}$cells of treated dogs showed a significant increase, especially after treatment, while $\mathrm{CD}^{+}$cells of untreated dogs decreased after the later acute stage.

treated dogs on the 14 th day after infection. After this point were not significantly different to the end of experiment. The numbers of $\mathrm{CD}^{+}$cells in either treated or untreated dogs showed significant increases on the 63rd and 82nd day compared with values before infection. The ratio of $\mathrm{CD}^{+} /$ $\mathrm{CD}^{+}$of treated dogs showed a significant increase from the 14 th to the 35 th day PI compared with values before infection, and this ratio was significantly higher than those of untreated dogs on the 14 th day. The numbers of CD21+ cells of treated dogs showed a slight decrease on the 7 th day and then increased from the 14th to the 35 th day compared with values before infection. Thereafter, they decreased on the 49th day, and increased again until the end of experiment. On the other hand, the numbers of CD $21^{+}$cells of untreated dogs showed also a slight decrease on the 7 th day and an increase from the 21 st until the 82 nd day compared with values before infection. However, no significant differences were seen in the values between treated and untreated dogs throughout the experiment except on 49th day (Fig. 3).

Babesia-specific IgG antibody levels: Specific anti-Babe- sial IgG antibody levels of treated and untreated dogs continued to rise throughout the infection period. The levels of $\mathrm{IgG}$ antibody increased on the 7th day. The values in treated dogs were significantly higher than those of untreated dogs immediately after clindamycin treatment on the 21 st day. The antibody levels of treated dogs were significantly higher than those of untreated during the chronic stage. A rapid humoral antibody response was observed in clindamycin-treated dogs on the 49th day PI when a slight relapse occurred. However, lower humoral antibody response in untreated dogs was observed, although relapses occurred (Fig. 4).

\section{DISCUSSION}

Clindamycin is suggested to act by binding to the $50 \mathrm{~S}$ ribosomal units of susceptible micro-organism, thereby inhibiting peptide bond formation [16]. This drug was reported to inhibit proliferation of Babesia canis from the canine-red blood cell-SCID mice [5]. Almost parasites of treated dogs during acute stage might be damaged or "inac- 


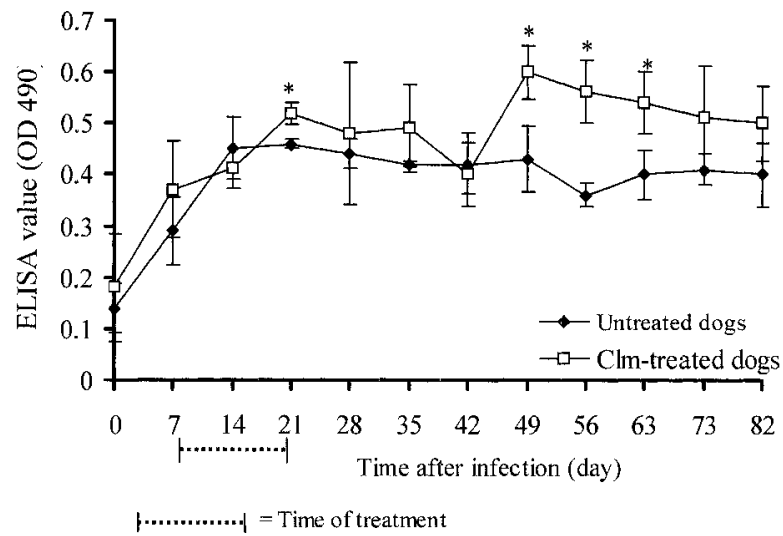

Fig. 4. Average reactivity of $\operatorname{IgG}$ in untreate $d($ ) and clindamycin-treated $(\square)$ of dogs infected with B. gibsoni. There was no significant difference between treated and untreated dogs in the antibody levels on the acute stage. In the chronic stage, the antibody levels of treated dogs were significantly higher than those of untreated dogs. A rapid humoral antibody response was observed in treated dogs on the 49th PI when a slight relapse occurred. However, lower humoral antibody response in untreated dogs was observed, although relapses occurred.

tivated" in view of their morphological changes. It might be speculated that anaemia and other clinical findings in the acute stage were resolved in treated dogs by the enhanced immune response.

It is known that both cellular and humoral factors are involved in immunity to babesiosis $[3,12,15]$. Severe Babesial infection on the acute stage is well known to induce immune-depression [12]. In the present study, CD4 cell levels of untreated dogs decreased on the acute stage, while those levels of treated dogs increased. Clindamycin did not diminish rapidly parasites from circulating blood, but might damage or inactivate them. During the acute stage, there were no significant different between IgG antibody levels. The damaged or "inactive" parasites of treated dogs might act not only as antigens to stimulate humoral immune response as same as "active" parasites of untreated dogs, but also as an immunomodulatory to enhance cellular immune response including the activation of $\mathrm{CD}^{+}$cells. The pivotal role of $\mathrm{CD}^{+}$cells in all infections is to aid in humoral immunity (antibody production) and cell mediated immunity (the proliferation of cytotoxic T cells, the activation of macrophage or the production of cytokines), which together are capable of directly inhibiting the growth of pathogens [17]. The ratio of $\mathrm{CD} 4^{+}$to $\mathrm{CD} 8^{+}$cells in peripheral blood may be used to determine lymphocyte function in clinical situations. An elevated $\mathrm{CD}^{+}$count implies increased lymphocyte reactivity because helper cells predominate, whereas a high $\mathrm{CD}^{+}$level implies depressed lymphocyte reactivity [19]. In the present study, the changes of $\mathrm{CD}^{+}$to $\mathrm{CD} 8^{+}$ratio showed the same tendency as those of $\mathrm{CD}^{+}$cells in both treated and untreated dogs, which might reflect that $\mathrm{CD}^{+}$cells are more dominant than $\mathrm{CD} 8^{+}$cell. The increased $\mathrm{CD} 21^{+}$cell levels on the last of experiment in either untreated or treated dogs during the last stage of experiment might indicate the proliferation of nonspecific B cells in Babesia infection.

Activation of macrophages is the early response to occur after Babesia infection [6]. In the present study, monocytes were higher in clindamycin-treated dogs than those in untreated dogs after clindamycin treatment. These facts might be related to two reasons; the 1st; clindamycin is an immune-enhancing antibiotic that induces positive effects on phagocytosis and enhances chemotaxis of macrophages [20], the 2nd; macrophages were activated with cytokines from the activated $\mathrm{CD} 4^{+}$cells cells as mentioned above.

In the present study, slight relapses were observed during the chronic stage in treated and untreated dogs. Slight or critical relapses during the later stage of babesiosis often occur even after the treatment [6]. Medical treatments are needed in critical cases. Clindamycin is applicable to such a case because of little side effects. It might be dependent on a patient's immunity against Babesia infection at that time whether clinical symptoms are slight or severe. During the chronic stage, Babesia antibody maintained high levels, however a rapid humoral antibody response was observed in treated dogs on the 49th day PI when a slight relapse occurred. While, lower humoral antibody responses in untreated dogs were observed, although relapses occurred. In our previous study, clindamycin treatment might induce resistance to challenge infection in cured mice from $B$. rodhaini-infection [21].

These results suggested that clindamycin might not eliminate rapidly parasites from peripheral blood, but damage parasites, which might stimulate efficiently humoral and cellular immunity against Babesia infection, and result in an improvement of clinical conditions. The detail role of lymphocyte subpopulations and Babesia-specific antibody on the treatment of clindamycin in dogs infected with B. gibsoni remained to be cleared.

ACKNOWLEDGEMENT. Authors thank Dr. Naochika Matsunuma, the Director of Medicinal Safety Research Laboratories, Sankyo Co., Ltd., Shizuoka, Japan for gift of beagles.

\section{REFERENCES}

1. Adachi, K, Yoshimoto, A., Hasegawa, T., Shimizu, T., Goto, Y. and Makimura, S. 1992. Anti-erythrocyte membrane antibodies detected in sera of dog naturally infected with Babesia gibsoni. J. Vet. Med. Sci. 54: 1081-1084.

2. Adachi,K., Watanabe, T., Yamane, S. and Makimura, S. 1993. Isolation of Babesia gibsoni piroplasms from infected erythrocytes of dogs. J. Vet. Med. Sci. 55: 487-490.

3. Adachi, K., Tateishi, M., Horii, Y., Nagatomo, H., Shimizu, T. and Makimura, S. 1994. Elevated erythrocytes-bound IgG value in dogs with clinical Babesia gibsoni infection. J. Vet. Med. Sci. 56: 757-759.

4. Ano, H., Makimura, S. and Harasawa, R. 2001. Comparison of partial ribosomal DNA sequences of Babesia gibsoni occurring in Miyazaki prefecture of Japan. J.Vet. Med. Sci. 63: 561-562.

5. Arai, S., Tsuji, M., Kim, S., Nakade,T., Kanno,Y. and Ishihara, 
C. 1998. Babesia canis infection in canine-red blood cell-substituted SCID mice. Int. J. Parasitol. 28: 1429-1435.

6. Birkenheuer, A. J., Levy, M.G., Savary, K.C.M., Gager, R.B. and Breitschwerdt, E.B. 1999. Babesia gibsoni infections in dogs from North Carolina. J. Am. Anim. Hosp. Assoc. 35: 125128.

7. Breitschwerd, E.B. 1990. Babesiosis. pp. 796-803. In: Infectious Diseases of Dog and Cat (Greene, C.E. ed.), Philadelphia: WB Saunders Company.

8. Brown, W.C. and Palmer, G.H. 1999. Designing blood-stage vaccines against Babesia bovis and B. bigemina. Parasitol. Today 15: 275-280.

9. Bruckner, D.A., Garcia, L.S., Shimizu, R. Y., Goldstein, E.J.K., Murray, P.M. and Lazar, G.S. 1984. Babesiosis: Problem in diagnosing using autolyzer. Am. J. Clin. Pathol. 84: 520-521.

10. Farwell, G.E., LeGrand, E.K. and Cobb, C.C. 1982. Clinical observations on Babesia gibsoni and Babesia canis infections in dogs. J. Am. Vet. Med. Assoc. 180: 507-511.

11. Grovies, M.G. and Vanniasinghem, J.A. 1970. Treatment of Babesia gibsoni infections with phenamidine isethionate. Vet. Rec. 86: 8-10.

12. Homer, M.J., Aguilar-Delfin, I., Telford III, S.R., Krause, P.J. and Persing, D.H. 2000. Babesiosis. Clin. Microbiol. Rev. 13: 451-469.

13 Ishikawa, E., Kawai, T. and Miyai, K. 1987. Antibody. pp.394-404. In: Enzyme Immunoassay. Igakushoin, Tokyo (in
Japanese).

14. Marley, S.E., Eberhard, M.L., Steurer, F.J., Ellis, W.L., McGreevy, P.B. and Ruebush II, T.K. 1997. Evaluation of selected antiprotozoal drugs in Babesia microti-hamster model. Antimicrobial Agents Chem. 41: 91-94.

15. Mota, M.M., Brown, N., Holder, A.A. and Jarra, W. 1998. Acute Plasmodium chabaudi chabaudi malaria infection induces antibodies which bind to the surfaces of parasitized erythrocytes and promote their phagocytosis by macrophages in vitro. Infect. Immun. 66: 4080-4086.

16. Plumb, D.C. 1999. Veterinary Drug Handbook. 3rd ed. Iowa State University.

17. Preston, P.M. and Jongejan, F. 1999. Protective immune mechanisms to tick and tick-borne disease of ruminants. Parasitol. Today 15: 255-258.

18. Rowin, K.S., Tanowitz, H.B. and Wittner M. 1982. Therapy of experimental babesiosis. Ann. Intern. Med. 97: 556-558.

19. Tizard, I.R. 2000. Veterinary Immunology: an Introduction. 6th ed. Texas. Saunders WB Company.

20. Van Vlem. B., Vanholder, R., De Paepe, P., Vogelaers, D. and Ringoir, S. 1996. Immunomodulating effect of antibiotics: Literature review. Infection (Jul-Aug) 24: 175-191.

21. Wijaya, A., Wulansari, R., Ano, H., Inokuma, H. and Makimura, S. 2000. Therapeutic effects of clindamycin and tetracycline on Babesia rodhaini infection in mouse model. $J$. Vet. Med. Sci. 62: 835-839. 